\title{
Publisher's Note: Refractory period of an excitable semiconductor laser with optical injection
}

[Phys. Rev. E 95, 012214 (2017)]

\author{
B. Garbin, A. Dolcemascolo, F. Prati, J. Javaloyes, G. Tissoni, and S. Barland \\ (Received 3 February 2017; published 10 February 2017)
}

DOI: 10.1103/PhysRevE.95.029901

This paper was published online on 26 January 2017 with an error in the Acknowledgments. The first sentence of the Acknowledgments should read as "J.J. acknowledges financial support from the Ramón y Cajal programme, project COMBINA (TEC2015-65212-C3-3-P) and from Direcció General de Recerca de les Illes Balears co-funded by the European Union FEDER funds as well as CNRS for supporting a visit at INLN where part of his work was developed." The Acknowledgments have been corrected as of 2 February 2017. The Acknowledgments are correct in the printed version of the journal. 